\title{
AVALIAÇÃO DAS DIFICULDADES DOS INGRESSOS NO CURSO DE LICENCIATURA EM QUIIMICA NO SERTÃO PERNAMBUCANO
}

\author{
AN EVALUATION ON THE DIFFICULTIES FOR \\ ENTERING UNDERGRADUATE CHEMISTRY \\ COURSES IN PERNAMBUCO
}

${ }^{1}$ Graduanda

em Química na

Universidade Federal

Rural de Pernambuco

(UFRPE)

${ }^{2}$ Docente na Faculdade

Frassinetti do Recife

(FAFIRE)

${ }^{3}$ Docente de Química

na Universidade

Federal Rural de

Pernambuco (UFRPE)

e doutorando no

Programa de Pós-

Graduação em Química

- Universidade Federal

de Pernambuco (UFPE)
Jéssica Itaiane Ramos de Souza ${ }^{1}$, Quesia dos Santos Souza Leite ${ }^{2}$, Bruno Silva Leite ${ }^{3}$

\section{RESUMO}

As experiências adquiridas durante o primeiro ano na universidade são muito importantes para a permanência do estudante no ensino superior. Porém, o processo de ensino e aprendizagem é, em geral, permeado de dificuldades e, no ensino de Química, não é diferente, muitos são os entraves para a construção do conhecimento. $O$ objetivo desta pesquisa foi identificar algumas dificuldades encontradas no início do curso de Química, enfrentadas pelos alunos da Universidade Federal Rural de Pernambuco, na Unidade Acadêmica de Serra Talhada. A pesquisa, de caráter quantitativo, deu-se por meio da aplicação de um questionário para 40 alunos do primeiro e do segundo períodos. Os resultados revelam algumas dificuldades apresentadas pelos estudantes, como a necessidade de abstração de conceitos químicos, apontando as dificuldades na formação básica como uma das principais causas. Estudos sobre o acompanhamento dos discentes 
são de grande importância, pois contribuem com a forma como percebemos o calouro, permitindo-nos entender suas dificuldades.

Palavras-chave: Dificuldades na aprendizagem. Ensino de Química. Ingressos em Química.

\section{INTRODUÇÃO}

As universidades brasileiras são bem recentes se as compararmos com as europeias. De acordo com Moreira et al. (2011), nas últimas décadas, um grande aumento da população universitária foi observado, com características bastante heterogêneas, como:

[...] classe social, gênero, objetivos, expectativas, trajetória acadêmica anterior, faixa etária, situação de trabalho, horário de estudo. Assim, percebeuse que a educação superior provocou mudanças expressivas nos estudantes, abrangendo o nível pessoal, profissional e social desses alunos (MOREIRA, 2011, p. 52).

Os cursos de licenciatura se formaram a partir da década de 1930, mas é a partir de 1968, com a criação das faculdades de educação nas universidades brasileiras, que a formação de professores tornou-se objeto de pesquisas (PEREIRA, 1999). Maldaner (2003) diz que, quando se discute a formação docente, faz-se necessário lembrar as reais condições da educação brasileira. Condições que envolvem vários fatores externos ao processo pedagógico e que vêm prejudicando 
a formação de professores em nosso país, destacando-se a precariedade da infraestrutura, a falta de interesse de alguns alunos, o desrespeito, a desvalorização por parte do governo e da sociedade, os baixos salários (SILVA, 2012), os espaços físicos e os materiais didáticos, que impossibilitam um ensino de melhor qualidade (CUNHA, 1999). Esses fatores, agregados a outras dificuldades no início da graduação, como a dificuldade de aprendizagem nas disciplinas, geralmente desestimulam o futuro professor, acarretando, muitas vezes, em desistência.

Em pesquisas sobre ensino de Química, é fundamental que se busque desenvolver mecanismos que facilitam a aprendizagem dos estudantes (NUÑES; RAMALHO, 2004). Nesse sentido, o objetivo de muitas dessas pesquisas é a criação de instrumentos que permitam descobrir as fragilidades intelectuais dos indivíduos e, com isso, desenvolver estratégias que contribuam para que os discentes possam construir o aprendizado de forma significativa e que minimizem as dificuldades o máximo possível (AUSUBEL, 1963; GALAGOSKY; ADURIZ-BRAVO, 2001; RIBOLDI et al., 2004).

Visando ao exposto acima, o objetivo deste trabalho é identificar dificuldades encontradas pelos estudantes nas disciplinas iniciais (básicas) do curso de licenciatura plena em Química.

\section{FUNDAMENTAÇÃO TEÓRICA}

As experiências durante o primeiro ano na universidade são muito importantes para a permanência dos estudantes no ensino superior e para o sucesso acadêmico deles (PASCARELLA; 
TERENZINI, 2005; REASON; TERENZINI; DOMINGO, 2006). Dos discentes, espera-se autonomia na aprendizagem, na administração do tempo e na definição de metas e estratégias para os estudos (SOARES et al., 2006). Apesar desse aumento na expectativa de responsabilidade individual por parte do aluno na própria formação e na adesão ao curso, verifica-se que certas características do ambiente universitário, tais como a oportunidade de interação com professores e de envolvimento em atividades extraclasse, favorecem a integração do aluno ao contexto universitário (CAPOVILLA; SANTOS, 2001; FIOR; MERCURI, 2003; KUH, 1995; KUH; HU, 2001).

Fundamentado no modelo tradicional de educação, no qual se compreende que, para ensinar, basta saber um pouco do conteúdo específico e utilizar algumas técnicas pedagógicas preferencialmente aquelas que priorizam a comunicação oral ou escrita -, o ensino de Química tem-se caracterizado pela supervalorização dos conteúdos curriculares e pela transmissão como método de ensino (SCHNEITZLER; ARAGÃO, 1995). Nessa concepção, a preocupação com a proposição e a retenção dos conteúdos colocam o professor no centro do processo de ensino-aprendizagem, na condição de grande detentor do conhecimento e de única fonte dos saberes (CAVALCANTE; SILVA, 2008). O aluno, por sua vez, é sujeito passivo no processo, e a apropriação dos conceitos ocorre de maneira meramente receptiva e individualizada, fazendo com que cada vez mais as dificuldades com relação às aulas aumentem. 0 professor geralmente não se importa em como abordar os conteúdos na aula, não busca novas formas de ensinar e, quando isso acontece, muitas vezes ele não sabe como usar as novas ferramentas e não se preocupa em aprender a lidar 
com elas. É o que ocorre, por exemplo, no uso dos recursos didáticos digitais (por meio de softwares educacionais, simuladores de processos e fenômenos químicos), em que há uma "substituição" do professor pela ferramenta. Da mesma forma, vê-se o uso de vídeos como tapa-buracos (MORAN, 1995), que são utilizados exclusivamente para preencher o tempo vago do aluno, sem se preocupar com a aprendizagem.

O processo de ensino e aprendizagem no ensino de ciências é permeado por entraves na construção do conhecimento. O epistemólogo francês Gaston Bachelard (1884-1962) dedicou parte dos estudos à reflexão sobre os erros que se constituem obstáculos e dificultam a aprendizagem dos conhecimentos científicos. Bachelard (1996) chamou de obstáculos epistemológicos as barreiras a serem superadas para se estabelecer e se desenvolver uma verdadeira mentalidade científica. Segundo Lecourt (1980), o obstáculo epistemológico tende a se manifestar mais decisivamente para mascarar o processo de ruptura entre o conhecimento comum e o conhecimento científico. Tratando de qualquer forma, sem se preocupar em como usar as ferramentas de ensino-aprendizagem, o docente pode fazer com que o aluno crie entraves para que esse processo ocorra.

Segundo Santos e Schnetzler (2010), a maioria das escolas tem dado ênfase à transmissão de conteúdos e à memorização de fatos, símbolos, nomes e fórmulas, deixando de lado a construção do conhecimento científico dos discentes e a desvinculação entre o conhecimento químico e o cotidiano. Essa prática tem influenciado negativamente na aprendizagem dos alunos, uma vez que eles não conseguem 
visualizar a relação existente entre o que estudam em sala de aula, a natureza e a vida cotidiana. Um pressuposto para a aprendizagem é que os estudantes sejam capazes de desenvolver o raciocínio abstrato da observação para a formulação de modelos (GALAGOSKY; ADURIZ-BRAVO, 2001). Isso é necessário porque a maior parte dos conceitos químicos é de natureza abstrata, e a compreensão deles depende de os estudantes terem capacidade de imaginar e modelar partes para poder incorporá-las mentalmente (MENDONÇA et al., 2006).

De acordo com Parente (1990) e Lopes (2007), pesquisas sobre dificuldades de aprendizagem têm revelado que muitos alunos constroem obstáculos que dificultam a aprendizagem de ciências. Gomes e Oliveira (2007) discutem sobre práticas e estratégias com o intuito de "facilitar" a aprendizagem, tais como

\footnotetext{
analogias, metáforas, imagens, modelos entre outras presentes nos materiais didáticos e amplamente utilizadas por docentes deveriam ser fonte de reflexão sobre suas implicações. Ainda que empregadas com a intenção de facilitar a compreensão de um determinado assunto, na realidade não auxiliam verdadeiramente, salvo em casos específicos muito bem trabalhados. Ao contrário, esses subterfúgios pedagógicos fazem com que sejam substituídas linhas de raciocínio por resultados e esquemas, o que se por um lado suscita atrativos e interesses, por outro se cristaliza intuições (GOMES; OLIVEIRA, 2007, p. 97).
}

Nesse sentido, essas práticas podem ser prejudiciais à aprendizagem. A assimilação de noções inadequadas, sejam elas advindas dos conhecimentos empíricos que o educando 
vivencia em seu cotidiano ou adquiridas na escola, poderá resultar na constituição de obstáculos epistemológicos (BACHELARD, 1996). Mortimer (1994; 1996) verificou que existe uma tendência entre os estudantes em considerar a regra do octeto como única resposta para a formação da ligação química e, consequentemente, explicar todas propriedades e mudanças das substâncias. Ele ainda ressalta a simplificação das respostas dos alunos, tendo como ponto fundamental apenas a regra do octeto, como um dogma inabalável (FERNANDEZ; MARCONDES, 2006).

A memorização de fatos, símbolos, nomes e fórmulas, deixando de lado a construção do conhecimento científico dos discentes, e a desvinculação entre o conhecimento químico e o cotidiano são, também, uma das dificuldades enfrentadas por alunos (SANTOS; SCHNETZLER, 2010). Essa prática influencia negativamente a aprendizagem, pois eles não conseguem fazer a relação do que veem em aula com o dia a dia. Um pressuposto para a aprendizagem é que os estudantes sejam capazes de desenvolver o raciocínio abstrato da observação para a formulação de modelos (GALAGOSKY; ADURIZ-BRAVO, 2001). Como a química é uma disciplina considerada abstrata, a compreensão e a formulação de modelos mentais são necessárias. Ou seja, os estudantes têm que ter a capacidade de imaginar e modelar partes para poder incorporá-las mentalmente (MENDONÇA et al., 2006).

Além dessa relação com o cotidiano, o professor deve levar em consideração o conhecimento que o aluno já tem (conhecimento prévio). Deve saber como trabalhar isso de forma a ajudar o aluno a mudar ou fortalecer o que já sabe. 
Quando esse conhecimento está em desacordo com os padrões aceitos atualmente pela comunidade científica, é conhecido como concepção alternativa, considerada a partir de interpretações equivocadas dos estudantes (BOO, 1998; REASON, ROBINSON, 1998). De acordo com Pozo et al. (1991), as concepções podem ser de origens espontânea, transmitida ou induzida e analógica. Fernandes et al. (2010) descrevem que

\begin{abstract}
As concepções alternativas de origens espontâneas são formadas devido ao senso comum e às experiências cotidianas dos alunos, baseadas principalmente na percepção dos fenômenos. As transmitidas ou induzidas são adquiridas pelos meios culturais e sociais dos estudantes antes da instrução formal da escola. Desse modo, o estudante chega à escola com ideias sobre os temas científicos que nem sempre são verdadeiras. Por sua vez, as de origem analógicas surgem devido a analogias criadas pelos estudantes ou pelos professores durante a abordagem dos conceitos científicos (FERNANDES, 2010, p. 20).
\end{abstract}

Algumas pesquisas no âmbito das concepções alternativas (CROSS et al., 1986; ROSS; MUNBY, 1991) indicam que o sucesso de estudantes em resolver problemas-padrões não significa que eles tenham adquirido um entendimento de química que Ihes permitisse aplicar satisfatoriamente determinados conceitos em outras situações, não abordadas previamente. Outra questão marcante é que os estudantes possuem dificuldades em relacionar conceitos em um arcabouço teórico coerente (SILVA et al., 2005, 2007), o que sugere que há necessidade de se procurar maneiras de ajudá-los no processo de criação de relações conceituais. 
Segundo Silva et al. (2005, 2007), o ensino básico não tem conseguido contribuir de forma mais efetiva para mudanças nas concepções dos estudantes, sendo que, na universidade, o processo ocorre de forma semelhante, mas com a agravante de que, nos cursos de licenciatura, formam-se futuros professores. Portanto, o professor deve identificar essas concepções e trabalhá-las com atividades para promover a evolução conceitual dos estudantes em direção às ideias consensuais da comunidade científica (SCHNETZLER; ARAGÃO, 1995). Assim, a existência de fortes relações entre os ensinos médio e superior, a necessidade de pesquisas voltadas às instâncias formativas de professores e a identificação das dificuldades no ingresso dos estudantes de licenciatura em Química na universidade motivaram o desenvolvimento desta pesquisa, buscando investigar quais as suas dificuldades no início da vida acadêmica.

\section{METODOLOGIA}

Com a intenção de verificar dificuldades apresentadas pelos discentes do curso de licenciatura em Química da Universidade Federal Rural de Pernambuco (UFRPE), no município de Serra Talhada - PE, buscamos identificar obstáculos encontrados nas disciplinas iniciais (básicas) da graduação.

O estudo seguiu os moldes da pesquisa quantitativa, que, segundo Fonseca (2002), traduz em números as opiniões e informações para, então, obter a análise dos dados e, posteriormente, chegar a uma conclusão. 
Inicialmente, foi elaborado um questionário com o objetivo de obter informações e opiniões dos alunos acerca das dificuldades enfrentadas no início do curso. O formulário constou de nove questões objetivas e subjetivas, sendo aplicado para 40 discentes do primeiro (turma da disciplina de Química Geral A - QGA) e do segundo períodos (turma da disciplina de Química Geral B - QGB), do segundo semestre de 2013, no curso de licenciatura em Química da UFRPE, localizada na Unidade Acadêmica de Serra Talhada (UAST), com tempo de aplicação de 50 minutos para cada turma. As perguntas do questionário são descritas a seguir.

Pergunta 1: Você teve monitoria?

( ) Sim ( ) Não.

Pergunta 2: Que fatores contribuíram para a escolha do curso:

a) Influência familiar b) Afinidade com a disciplina

c) Afinidade com a área (Ciências Exatas) d) Remuneração e) Nota do ENEM f) Outros:

Pergunta 3: Qual sua expectativa antes de entrar no curso? Ela foi correspondida?

Pergunta 4: Você acha que a química, por ser uma disciplina bastante abstrata, dificulta o ensino e aprendizagem em sala de aula? Por quê?

Pergunta 5: Você teve muita dificuldade no processo de adaptação ao ensino acadêmico? Quais? 
Pergunta 6: Enumere em relação ao grau de dificuldade no que diz respeito a:

( ) Metodologia de avaliação

( ) Autonomia nos estudos

( ) Linguagem técnica dos livros

( ) Metodologia adotada pelos professores

( ) Horário do curso

( ) Formação básica

( 1 ) Pouco

( 3 ) Médio

( 5 ) Muito difícil

Pergunta 7: Qual o conteúdo mais difícil de ser assimilado durante a disciplina de Química Geral (A e B)? Justifique.

a) Soluções

b) Estequiometria

c) Modelos atômicos

d) Ligações químicas

e) Cinética

f) Outro: 
Pergunta 8: Os conteúdos vistos no ensino médio contribuíram para a aprendizagem dos conteúdos na Universidade? Por quê?

Pergunta 9: Proponha alternativas para minimizar a dificuldade encontrada nas disciplinas iniciais de Química.

As perguntas foram realizadas com o objetivo de conhecer e, posteriormente, avaliar fatores que contribuem ou influenciam na aprendizagem dos discentes, destacando possíveis dificuldades apresentadas por eles no início do percurso acadêmico. Cabe ressaltar que o curso de Química oferece, para os ingressos, monitoria nas duas disciplinas em questão. Os dados obtidos por meio da aplicação do questionário foram analisados e encontram-se descritos na seção a seguir.

\section{RESULTADOS E DISCUSSÕES}

As respostas aos questionários foram apresentadas conforme escrito pelos discentes, preservando-se erros de digitação, de redação de texto etc. Eliminaram-se, ainda, os nomes e dados que poderiam identificar os sujeitos.

Com relação à participação nas aulas de monitoria, muitos dos estudantes não residem na cidade em que se localiza a universidade. Assim, deslocam-se todos os dias no horário da aula (noite) para os estudos. A monitoria, em seu turno, é no período da tarde, o que dificulta a participação daqueles que são de outra cidade. Além disso, como o curso é noturno, alguns alunos trabalham durante 0 dia. Os resultados 
numéricos confirmam tais afirmações. Aproximadamente $67,5 \%$ dos alunos responderam que não participam das aulas de monitoria por serem de outras cidades ou por trabalharem. Dos $32 \%$ de alunos que participaram da monitoria, apenas $11 \%$ responderam que sempre vão às aulas, e cerca de $70 \%$ só participam delas quando estão perto de avaliações da disciplina. Embora o curso ofereça monitoria para os alunos ingressos, poucos têm participado.

O segundo questionamento teve como objetivo conhecer que fatores levaram os discentes a escolherem o curso de licenciatura em Química na UAST. Os resultados revelaram a escolha desses alunos, conforme descrito no Gráfico 1.

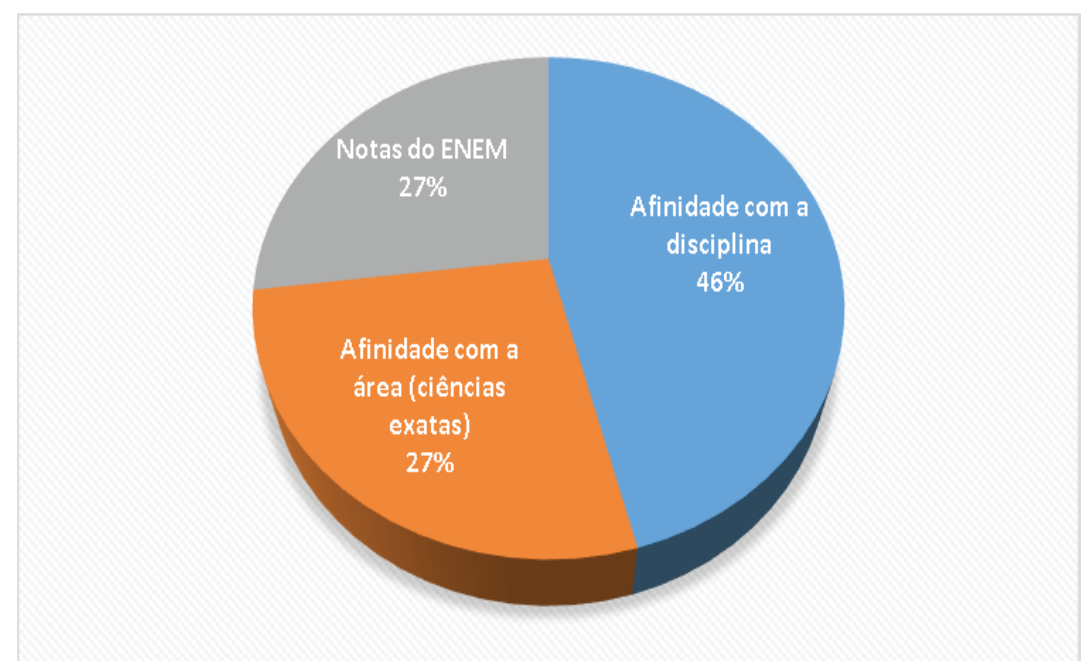

Gráfico 1 - Fatores que contribuíram para a escolha do curso.

Como observado, nenhum dos discentes optou pela escolha do curso devido à influência familiar ou à remuneração. Os dados revelaram que $46 \%$ dos discentes escolheram o curso de Química por afinidade com a disciplina; por afinidade com a área das Ciências Exatas, temos 27\%; e o mesmo percentual 
devido à nota no Exame Nacional do Ensino Médio (ENEM). É relevante informar que o curso de Química na UAST iniciou as atividades no primeiro semestre de 2007, quando a seleção era realizada por meio do vestibular (com primeira e segunda fases). Desde 2009, o ingresso para o curso de se dá por meio do ENEM.

No que diz respeito à terceira pergunta do questionário aplicado ("Qual sua expectativa antes de entrar no curso? Ela foi correspondida?"), observamos que muitos alunos afirmaram que as expectativas ao entrarem no curso foram correspondidas. Duas das respostas foram: "A expectativa era de enaltecer os conhecimentos já adquiridos. Foi muito bem correspondida. Tenho aprendido bastante com as novas descobertas" e "Crescer de forma a aumentar meu conhecimento na área. Minhas expectativas estão sendo correspondidas". Além dessas, houve respostas que ressaltavam a afirmação de identificação com o curso.

Por ser uma disciplina de conteúdo considerado abstrato, geralmente, a Química trata de fenômenos que não podem ser observados a olho nu e que, portanto, requerem a imaginação do aluno para tentar entender determinados conceitos. Pozo e Crespo (2006) consideram que a concepção inadequada de como o conhecimento científico é elaborado interfere no avanço de uma abordagem construtivista no ensino de ciências, ou seja, a construção do conhecimento do sujeito a partir da interação com o meio (BECKER, 1992). Quando questionados sobre o fato de a abstração presente na Química dificultar a aprendizagem, todos os discentes afirmaram que sim, essa característica é um obstáculo, e relataram que "alguns 
fenômenos são difíceis de ser compreendidos e explicados". Já outros acreditam que o papel do professor pode contribuir ou não para o entendimento da química: "[...] isso vai depender de quem ministra a aula" e "pode ser facilitada pelo professor".

Sobre as dificuldades no processo de adaptação ao ensino superior, $72 \%$ dos discentes relataram que tiveram dificuldades. Algumas foram descritas ou justificadas das seguintes maneiras: "[...] cheguei com uma mente que era como no ensino médio"; "talvez por questão da base, não ter tido um ensino médio adequado"; "além da mudança de ritmo, a deficiência de alguns conhecimentos do ensino médio". Nessas afirmações, percebemos que esses alunos acreditavam que o ensino de Química na graduação seria semelhante ao do ensino médio, o que, em alguns casos, os conduz à impressão de que seria uma disciplina "difícil". Outro aluno afirmou que a "[...] maior dificuldade é ajustar estudo e trabalho", o que reflete a realidade de um curso que ocorre apenas no horário noturno, cujos discentes, em sua maioria, trabalham durante o dia.

O Gráfico 2, a seguir, apresenta as respostas dos discentes quanto ao grau de dificuldade em alguns tópicos. 


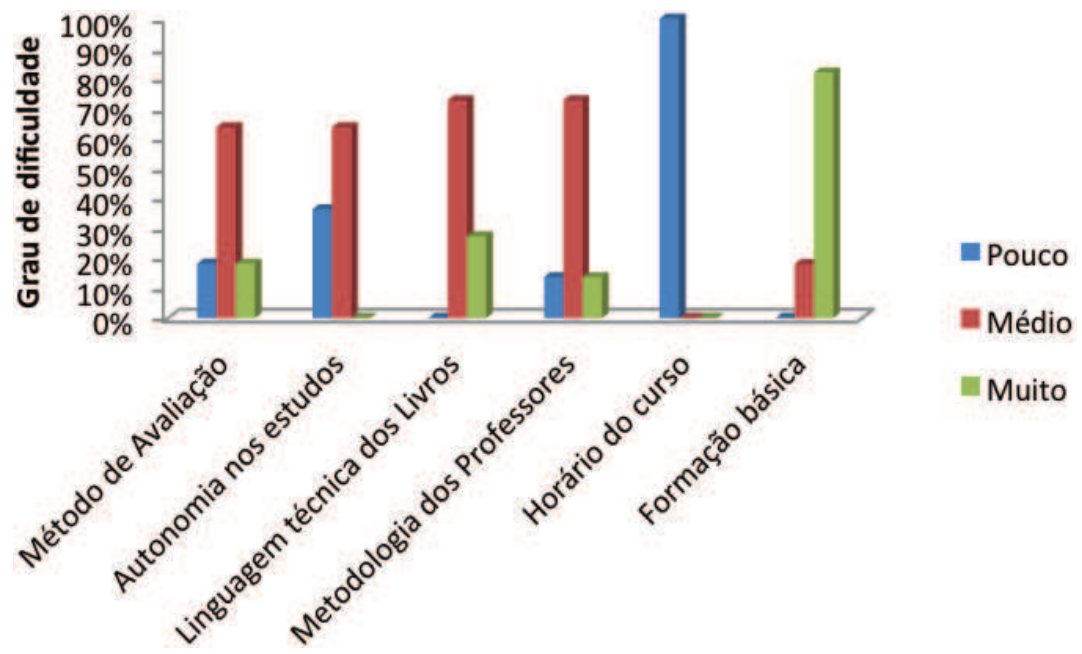

Gráfico 2 - Porcentagem do grau de dificuldade em relação os tópicos sugeridos.

Os resultados indicam que a formação básica é considerada pelos discentes como um fator de grande dificuldade no curso de Química. Esse tópico foi apontado como o de maior grau de dificuldade (80\%). O item que causou menos dificuldade nos alunos foi o horário do curso (noturno), conforme o que todos afirmaram nas respostas. Com relação aos demais tópicos, a maioria considerou de dificuldade média.

No que se refere aos conteúdos, a disciplina de "Química Geral A" apresenta como conteúdos da ementa: reações químicas, soluções, estequiometria, modelos atômicos e ligações químicas. Já a disciplina de "Química Geral B" dispõe dos conteúdos de: cinética química, termoquímica, equilíbrio químico e eletroquímica. No questionamento 7 , os discentes apontaram ter dificuldades apenas nos conteúdos de estequiometria (50\%) e cinética química (50\%). Vários estudos foram feitos sobre a dificuldade de compreensão dos conteúdos citados, por exemplo, os trabalhos de Savoy 
(1988), Andersson (1990) e Arasasingham et al. (2004). Esses estudiosos citam a dificuldade de abstração e transição entre os níveis macroscópicos e microscópicos, bem como em símbolos de representação da matéria no conteúdo de estequiometria.

Quando questionados sobre as contribuições do ensino médio para a graduação, os discentes justificaram que a falta de base naquela etapa do aprendizado é o maior obstáculo para a melhor compreensão dos assuntos vistos (como observado na pergunta 7 do questionário). Podemos, aqui, inferir a importância da aprendizagem significativa que ocorre quando a nova informação ancora-se em conceitos relevantes (subsunçores) preexistentes na estrutura cognitiva do aprendiz (AUSUBEL, 1963; NOVAK; GOWIN, 1984). As respostas de alguns discentes foram: "Vi muito rápido no ensino médio e tive que aprender em muito pouco tempo"; "Não ter uma base na disciplina de Física e de Química"; e "Devido à falta de base no assunto". Cabe ressaltar que cerca de $44 \%$ responderam que o ensino médio contribuiu para a compreensão do conteúdo no ensino superior. Uma das respostas é descrita a seguir: "Sim, pois tive uma boa base no ensino médio e não tive tanta dificuldade".

Por fim, a última questão solicitava que os discentes propusessem alternativas para minimizar as dificuldades encontradas no início do curso. Dentre as respostas, destacamos as sugestões de alguns discentes que acreditam que: "A alternativa seria investir na base (no ensino médio) para que os alunos cheguem na Universidade mais preparados"; "professores terem mais paciência com os alunos que estão iniciando a vida acadêmica, até que eles estejam preparados" e 
"criação de novos métodos de ensino que não obedeçam tanto ao tradicionalismo". Podemos refletir a partir dessas respostas sobre a importância de o professor apresentar aos alunos um ensino voltado para uma aprendizagem significativa, que acreditamos ser possível para uma efetiva contribuição ao ensino de Química no início da graduação desses discentes.

\section{CONSIDERAÇÕES FINAIS}

Por meio do questionário aplicado aos alunos do início do curso de licenciatura em Química, observamos que eles apresentam dificuldades no aprendizado e na assimilação dos conceitos básicos da área e que, quando ingressam na universidade, esses obstáculos se tornam mais enfáticos. Os alunos, em nossas discussões, apresentaram consciência do papel do professor na mediação do conhecimento de forma a minimizar os problemas enfrentados, isso porque é através da comunicação e da interação entre educador e educando que o conhecimento é construído e a aprendizagem pode acontecer. Ademais, o aluno do ensino médio precisa de maior atenção para conseguir chegar à universidade com menos obstáculos a serem enfrentados.

Precisamos "olhar" o estudante de forma diferenciada e acolhedora, principalmente no momento do ingresso dele no curso superior, por ser o primeiro ano de graduação, um período, em alguns casos, crítico para o desenvolvimento e o ajustamento acadêmico. Nessa etapa, o estudante experimenta vários desafios provenientes das atividades acadêmicas que são inerentes à transição da adolescência para 
a vida adulta e que, quando confrontados com as exigências da vida universitária, se constituem um obstáculo a ser superado.

\section{REFERÊNCIAS}

ANDERSSON, B. Pupils' conceptions of matter and its transformations (age 12-16). Studies in Science Education, v. 18, p. $53-85,1990$.

ARASASINGHAM, R. D.; TAAGEPERA, M.; POTTER, F.; LONJERS, S. Using knowledge space theory to assess student understanding of stoichiometry. Journal of Chemical Education, v. 81, n. 10, p. 1.517-1.524, 2004.

AUSUBEL, D. P. The psychology of meaningful verbal learning. New York: Grune and Stratton, 1963.

BACHELARD, G. A formação do espírito científico: contribuição para uma psicanálise do conhecimento. Tradução: Estela dos Santos Abreu. Rio de Janeiro: Contraponto, 1996.

BECKER, F. O que é o construtivismo? Revista de Educação $A E C$, v. 21, n. 83, p. 7-15, 1992.

BOO, H. K. Students' understandings of chemical bonds and the energetic of chemical reactions. Journal of Research in Science Teaching, v. 35, n. 5, p. 569-581, 1998.

CAPOVILLA, S. L.; SANTOS, A. A. A. Avaliação da influência de atividades extramuros no desenvolvimento pessoal de universitários. Psico-USF, v. 6, p. 49-58, 2001.

CAVAlCANTE, D. D.; SILVA, A. F. A. Modelos didáticos de professores: concepções de ensino-aprendizagem e experimentação. In: ENCONTRO NACIONAL DE ENSINO 
DE QUÍMICA, 14. 2008. Curitiba, Anais... Curitiba: UFPR, 2008.

CROSS, D.; AMOUROUX, R.; CHASTRETTE, M.; LEBER, J.; FAYOL, M. Conceptions of First-Year University Students of the Constituents of matter and the notions of acids and bases. European Journal of Science Education, v. 8, n. 3, p. 305-313, 1986.

CUNHA, M. I. O bom professor e sua prática. Campinas: Papirus, 1999.

FERNANDES, L. S.; CAMPOS, A. F.; JUNIOR, C. A. C. M. Concepções Alternativas dos Estudantes sobre Ligação Química. Experiências em Ensino de Ciências, v. 5, n. 3, p. 19-27, 2010.

FERNANDEZ, C.; MARCONDES, M. E. R. Concepções dos estudantes sobre ligação Química. Química Nova na Escola, v. 24, n. 2, p. 20-24, 2006.

FIOR, C. A.; MERCURI, E. Formação universitária: o impacto das atividades não obrigatórias. In: MERCURI, E.; POLYDORO, S. A. J. (Orgs.), Estudante universitário: características e experiências de formação. Taubaté: Cabral, 2003, p. 129-154.

FONSECA, J. J. S. Metodologia da pesquisa científica. Fortaleza: UEC, 2002.

GALAGOSKY, L.; ADURIZ-BRAVO, A. Modelos y analogías en la enseñanza de las Ciencias Naturales. El concepto de modelo didáctico analógico. Enseñanza de las Ciencias, v. 19, n. 2, p. 231-242, 2001.

GOMES, H. J. P.; OLIVEIRA, O. B.; Obstáculos epistemológicos no ensino de ciências: um estudo sobre 
suas influências nas concepções de átomo. Ciência $e$ cognição, v. 12, 2007.

$\mathrm{KUH}, \mathrm{G}$. D. The other curriculum: out-of-class experiences associated with student learning and personal development. The Journal of Higher Education, v. 66, n. 2, p. 123-155, 1995.

KUH, G. D.; HU, S. The effects of student-faculty interaction in the 1990s. The Review of Higher Education, v. 24, n. 3, p. 309-332, 2001.

LECOURT, D. Para uma crítica da epistemologia. Lisboa: Assírio Alvim, 1980.

LOPES, A. C. Livros didáticos: Obstáculos ao aprendizado da ciência química. Química Nova, v. 15, n. 3, p. 254-261, 2007.

MALDANER, O. A. A Formação Inicial e Continuada de Professores de Química - Professores/Pesquisadores. Ijuí: UNIJUÍ, 2003.

MENDONÇA, P. C. C.; JUSTI, R.; OLIVEIRA, M. M. Analogias sobre Ligações Químicas elaboradas por alunos do ensino médio. Revista Brasileira de Pesquisa em Educação em Ciências, v. 6, n. 1, p. 22-34, 2006.

MORAN, J. M. O vídeo na sala de aula. Comunicação $e$ Educação, v. 2, p. 27-35, 1995.

MOREIRA, A. C.; KIMA, F. M.; SILVA, P. N. A difícil tarefa de acadêmicos de curso noturno em conciliar trabalho e Estudo. Interdisciplinar: Revista Eletrônica da Univar, n. 6, p. 51-56, 2011.

MORTIMER, E. F. O Significado das fórmulas Químicas. Química Nova na Escola, n. 3, p. 19-21, 1996. 
MORTIMER, E. F. Regra do octeto e teoria da ligação química no ensino médio: dogma ou ciência? Química Nova, v. 17, n. 2, p. 243-252, 1994.

NOVAK, J. D.; GOWIN, D. B. Learning how to learn. Cambridge: Cambridge University Press, 1984.

NUÑES, I. B.; RAMALHO, B. L. Fundamentos do EnsinoAprendizagem das Ciências Naturais e da Matemática: o novo ensino médio. Porto Alegre: Sulina, 2004.

PARENTE, L. T. S. Bachelard e a química: no ensino e na pesquisa. Fortaleza: Ed. da Universidade Federal do Ceará, 1990.

PASCARELLA, E. T.; TERENZINI, E. T. How college affects students: A third decade of research. v. 2. San Francisco: Jossey-Bass, 2005.

PEREIRA, J. E. D. As licenciaturas e as novas políticas educacionais para a formação docente. Educação \& Sociedade, n. 68, 1999.

POZO, J. I.; CRESPO, M. A. G. A aprendizagem e o ensino de ciências - do conhecimento cotidiano ao conhecimento científico. 5. ed. Porto Alegre: Artmed, 2006.

POZO, J. I.; CRESPO, M. A.; GOMEZ, L.; SERRANO, M.; SANZ, A. Procesos cognitivos en la comprensión de la ciencia: las ideas de los adolescentes sobre la química. Madrid: Centro de Publicaciones del Ministerio de Educación y Ciencia, 1991.

REASON, R. D. ROBINSON, W. R. An alternative framework for chemical bonding. Journal of Chemical Education, v. 75, n. 9, p. 1.074-1.075, 1998. 
REASON, R. D.; TERENZINI, P. T.; DOMINGO, R. J. First things first: Developing academic competence in the first year of college. Research in HigherEducation, v. 47, p. 149-175, 2006.

RIBOLDI, L.; PLIEGO, O.; ODETTI, H. El enlance químico: Una conceptualización poco comprendida. Enseñanza de lasciencias, v. 22, n. 2, p. 195-212, 2004.

ROSS, B.; MUNBY, H. Concept Mapping and Misconceptions: a Study of High-School Students' Understandings of Acids and Bases. International Journal of Science Education, v. 13, n. 1, p. 11-23, 1991.

SAVOY, L. G. Balancing chemical equations. School Science Review, v. 69, n. 249, p. 713-720, 1988.

SCHNETZLER, R. P.; ARAGÃO, R. M. R. Importância, sentido e contribuições de pesquisa para o ensino de química. Revista Química Nova na Escola, n. 1, 1995.

SILVA, D.N. A desmotivação do professor em sala de aula, nas escolas públicas do município de São José dos Campos - SP. 2012. 52p. Monografia. Universidade Tecnológica Federal do Paraná - Campus Curitiba. 2012.

SILVA, S. M.; EICHLER, M. L.; SALGADO, T. D. M.; DEL PINO, J. C. Concepções alternativas de calouros de química para os estados de agregação da matéria, solubilidade e a expansão térmica do ar. In: $V$ ENCONTRO NACIONAL DE PESQUISA EM EDUCAÇÃO EM CIÊNCIAS, Bauru. Anais... Bauru: ABRAPEC, 2005.

SILVA, S. M.; MORAIS, L.; EICHLER, M. L; SALGADO, T. D. M.; DEL PINO, J. C. Concepções alternativas de calouros de química para os conceitos de termodinâmica e equilíbrio químico. In: VI ENCONTRO NACIONAL DE 
PESQUISA EM EDUCAÇÃO EM CIÊNCIAS, Florianópolis. Anais... Florianópolis: ABRAPEC, 2007.

SOARES, A. P.; ALMEIDA, L. A., DINIZ, A. M.; GUISANDE, M. A. Modelo multidimensional de ajustamento de jovens ao contexto universitário (MMAU): Estudo com estudantes de ciências e tecnologias versus ciências sociais e humanas. Análise Psicológica, v. 24, n. 1, p. 1527. 2006.

\begin{abstract}
The experiences along the first year at the university are very important for the students' permanence in undergraduate education. However, the process of teaching and learning is usually filled with difficulties and in Chemistry teaching it is not different; there are many barriers to the construction of knowledge. The aim of this research was to identify some difficulties in the beginning of the Chemistry course by students at the Federal Rural University of Pernambuco in the Academic Unit of Serra Talhada. The quantitative research consisted on the application of a questionnaire to 40 students from the first and second periods. The results reveal some difficulties faced by the students such as the need for abstracting Chemistry concepts, pointing out difficulties in basic education as the main cause. Studies on students monitoring are of great importance, because they contribute to the way we perceive the university freshmen, allowing us to understand their difficulties.
\end{abstract}

Keywords: Learning difficulties. Chemistry Teaching. Chemistry Students. 


\section{Jéssica Itaiane Ramos de Souza}

Unidade Acadêmica de Serra Talhada (UAST). Universidade Federal Rural de Pernambuco (UFRPE). Estudante de graduação do curso de licenciatura em Química da UFRPE, na Unidade Acadêmica de Serra Talhada, é bolsista do Programa Institucional de Bolsas de Iniciação científica (PIBIC).

jeitaiane@gmail.com

\section{Quesia dos Santos Souza Leite}

Colégio Souza Leão. Faculdade Frassinetti do Recife (FAFIRE). Docente em Língua Portuguesa e especialista em Linguística Aplicada no Ensino da Língua Portuguesa. Desenvolve pesquisas em variação linguística, formação de professores e leitura científica.

quesiadss@yahoo.com.br

\section{Bruno Silva Leite}

Unidade Acadêmica de Serra Talhada (UAST). Universidade Federal Rural de Pernambuco (UFRPE). Programa de PósGraduação em Química - Universidade Federal de Pernambuco (UFPE). Docente de Química. É mestre em Ensino de Ciências e realiza doutoramento em Química Computacional. Desenvolve pesquisas em Ensino de Química com aplicação das TICs no Ensino; Instrumentação para o Ensino; Formação de professores. É coordenador do grupo de pesquisa de Investigação de Práticas Metodológicas no Ensino de Química e do Laboratório para Elaboração e Utilização de Tecnologias no Ensino de Química.

bruno.leite@uast.ufrpe.br 
